\title{
CULPABILIDAD Y SUJETO EN LA OBRA DE JUAN BUSTOS RAMIREZ*
}

Jaime Couso**

\begin{abstract}
Misión de la categoría de culpabilidad e insuficiencias de la idea de culpabilidad como reprochabilidad individual; Diversas respuestas a la crisis de la idea de culpabilidad; Culpabilidad como exigibilidad social en Bustos Ramirez; La exigibilidad social como contenido material de la culpabilidad; Valoración y crítica; Autonomía comunicativa y culpabilidad en Kindhäuser; Autonomía deliberativa y culpabilidad en Günther; Bibliografía.
\end{abstract}

Una de las muchas áreas de la teoría y la dogmática penal en las que Bustos Ramírez incursionó con planteamientos innovadores es la de la culpabilidad, y en particular, la de la imputabilidad. En este trabajo me propongo, tras sintetizar las razones de la crisis de la concepción normativa de la culpabilidad, destacar los aportes de la concepción de Bustos Ramírez para el debate contemporáneo sobre el fundamento material de esa categoría del delito, señalando también algunas de sus limitaciones. Para resumir desde ya mi planteamiento, considero que Bustos Ramírez pone tempranamente de relieve un aspecto fundamental para esta discusión, a saber, que si bien la condición de persona ("sujeto responsable", en su nomenclatura) es atribuida al individuo a partir de criterios normativos, la culpabilidad requiere algo más que esa atribución normativa, a saber, "exigibilidad social" del cumplimiento de la norma. En efecto, teniendo en cuenta la dimensión histórica y política conflictiva de la atribución del papel de sujeto, Bustos Ramírez afirma una co-responsabilidad social por el conflicto criminal, que puede llegar a excluir la culpabilidad del sujeto, sin que por ello éste pierda su condición de tal, que se deriva de su dignidad humana. Esa perspectiva crítica sobre las condiciones de la atribución del rol de persona, me parece, todavía tiene mucho que aportar al debate sobre el fundamento material de la culpabilidad, sobre todo para superar una consideración formal y abstracta de las relaciones entre persona y ordenamiento jurídico. Por otra parte, sin embargo, me parece que la concepción de Bustos Ramírez no presta la debida atención a la relación entre culpabilidad y autonomía política del sujeto sometido a las exigencias del Derecho, que los planteamientos contemporáneos inspirados en la teoría del discurso sí consideran, en cambio. Con todo, los déficits de horizonte crítico de que adolecen estos otros planteamientos, se pueden superar precisamente a partir de una perspectiva

\footnotetext{
* Una parte importante de los planteamientos que haré en este trabajo está desarrollada con más detalle en Couso, "Fundamentos...", pp. 189 y ss. y passim. Otra parte es inédita, en particular, el análisis de la concepción de Günther ("Schuld..."), así como la comparación de su concepción y la de Kindhäuser ("Rechtstreue...”) con la de Bustos Ramírez.

** Profesor de Derecho penal, Universidad Diego Portales.
} 
Couso - Culpabilidad y sujeto en la obra de Juan Bustos Ramírez

sociopolítica de los problemas de culpabilidad, como la que introduce de Bustos Ramírez. Por esa razón, mi propia concepción busca complementar ambos planteamientos, a través de un concepto material de culpabilidad que sea función de la autonomía política del ciudadano, en relación con la norma penal, y de su situación histórica-concreta en relación con los bienes protegidos por ella.

\section{Misión de la categoría de culpabilidad e insuficiencias de la idea de culpabilidad como reprochabilidad individual}

A partir de la teoría normativa de la culpabilidad, que la define como la reprochabilidad individual del autor por haberse decidido por el injusto siendo que podía haber obrado conforme a derecho, esta categoría del delito desempeña una "misión individualizadora-garantista", es decir, una misión de individualización de la imputación y garantía de la autonomía individual. La fundamentación de esa misión originalmente se asocia a una concepción retributiva de la pena. En el seno de un Derecho penal preventivo, el sentido de esa misión individualizadoragarantista puede ilustrarse de la siguiente manera: si el injusto expresa un juicio general sobre la conducta, que sintetiza las condiciones que la hacen en abstracto merecedora y necesitada de pena, la culpabilidad expresa un juicio individual sobre el comportamiento del autor concreto, y sintetiza las razones que hacen justo o legítimo imponerle una pena (necesaria para la prevención delictual). Pero en qué medida un Derecho penal preventivo puede asignar tal misión a la culpabilidad es algo que, precisamente ese cambio en el punto de partida, vuelve controvertido. La obra de Bustos Ramírez en esta materia puede verse como un momento de esa controversia.

La teoría normativa de la culpabilidad, basada en la doctrina de la libertad de voluntad y en la reprochabilidad individual del autor que "podía haber actuado de otro modo", entró en una profunda crisis en Alemania en los años 60 del siglo pasado. La crisis de esta concepción de la culpabilidad, que tiene diversas manifestaciones, tuvo como hito el cuestionamiento, debido especialmente a Engisch, de la posibilidad de demostrar empíricamente la base del juicio de reproche, el "poder actuar de otro modo"1.

La crítica, aunque no era del todo nueva, alcanza gran repercusión y se convierte progresivamente en una crisis de los fundamentos del Derecho penal de culpabilidad ${ }^{2}$. En efecto, el Derecho penal de culpabilidad convencional se basa en una sucesión de ideas, de las que el "poder actuar de otro modo" es la base. Roxin expone, con propósitos de crítica, esta sucesión de ideas, del siguiente modo: 1) El

\footnotetext{
1 "Una prueba empírica satisfactoria sobre el punto tendría que apoyarse en el experimento de poner a la misma persona en la misma situación, para ver si alguna vez se produce un comportamiento distinto al delito. Pero un experimento de esas características fracasaría" (Engisch, citado por Pérez Manzano, “Culpabilidad y prevención...”, p. 93).

2 Pérez Manzano, ibíd. pp. 94 y ss., con amplias referencias bibliográficas.
} 
delincuente infringe la ley penal, pese a que podía haber actuado conforme a ella; 2) este comportamiento antijurídico cometido libremente, permite elevar un reproche moral al autor: culpabilidad es reprochabilidad; 3) la reprochabilidad del hecho legítima al Estado para retribuirlo con un mal, correspondiente a la medida de la culpabilidad; y, 4) la pena retributiva es el medio más adecuado para reprimir comportamientos socialmente dañosos no evitables de otra forma ${ }^{3}$. La crítica de Engisch afecta seriamente a la primera de estas ideas, amenazando con hacer caer toda la sucesión, como las fichas del dominó que, alineadas una tras otra, se vienen abajo todas por efecto de la caída de la primera ("teoría del dominó") ${ }^{4}$.

La crisis del Derecho penal de culpabilidad, en todo caso, va más allá de la primera idea de la sucesión, llegando a abarcarlas a todas ${ }^{5}$.

Así, la vinculación entre Derecho y moral establecida por el entendimiento de la culpabilidad como reprochabilidad, también es objeto de la crítica, pues, en primer lugar, el Estado no tiene legitimación para elevarse moralmente sobre el ciudadano 6 , en segundo lugar, "no se puede formular responsablemente un reproche contra una persona que se conoce de un modo tan selectivo y rudimentario como la conoce el juez penal"'7.

En seguida, la relación de justicia entre infracción reprochable de la norma (obviando por un momento la objeción recién apuntada) y retribución, tampoco resiste a un análisis racional, ni siquiera si se recurre a fundamentaciones idealistas (recurso que, por lo demás, en un Estado liberal no hay por qué aceptar). Con palabras de Kindhäuser, quien cuestiona la teoría hegeliana de la pena, retomada por Köhler y por Zaczyk: "En primer lugar, no queda clara la supuesta necesidad racional de la relación entre infracción de la norma y pena: una lesión del Derecho también puede ser compensada a través de la reparación. Pero incluso si se toma la palabra al postulado idealista y se parte de una mala voluntad del delincuente que perdura más allá del delito, según mi parecer sigue siendo un enigma por qué y cómo puede hacerse desaparecer nuevamente esa mala voluntad por medio de la pena o restituirse la vigencia del Derecho mediante su reconocimiento. Sólo el propio autor puede cambiar su voluntad y sólo el propio autor puede desistir de su

\footnotetext{
${ }^{3}$ Cfr. Roxin, “¿Qué queda de la culpabilidad...”, p. 671.

${ }^{4}$ La imagen es usada por Gimbernat, "¿Tiene un futuro...?”, p. 142: "Nos encontramos con una por así decir, "teoría del dominó": la crisis de la idea de la culpabilidad trae consigo la de la pena; y sin pena no puede haber Derecho penal, y sin éste tampoco una ciencia del Derecho penal en sentido tradicional".

${ }^{5}$ Cfr. Roxin, “¿Que queda de la culpabilidad...?”, pp. 672-673.

${ }^{6}$ Roxin, “¿Qué queda de la culpabilidad...?”, p. 672.

7 Hassemer, “¿Alternativas...?”, p. 480. Cfr. también Roxin, como en la nota anterior: aunque el Estado tuviese legitimación para ello, "tampoco estaría en condiciones para emitir un juicio moralmente válido sobre el acusado. Pues para ello debería abordar toda la historia de su vida y poder contemplar todos los rincones de su corazón. Y esto es decididamente imposible en un proceso penal que discurre según reglas formalizadas y se limita al enjuiciamiento de un único hecho punible".
} 
negativa a reconocer el Derecho"s.

En fin, por último, se critica la vinculación de la teoría normativa de la culpabilidad a una teoría penal desprovista de fines, que reprime el delito sin preocuparse de lo necesario para prevenirlo?.

Como ya puede deducirse de las críticas a la teoría normativa de la culpabilidad, su consecuencia no sólo se produce en el terreno político-criminal, sino que la teoría penal se ve forzada a renovar la reflexión acerca de la verdadera legitimación del Derecho penal, y de la pena. Ello tendrá consecuencias importantes para el concepto material de culpabilidad.

Pero precisamente puede considerarse que una herencia fundamental de la teoría normativa de la culpabilidad es la exigencia de justicia en la imposición de pena a un individuo concreto, una justicia que no le puede venir prestada a la pena por su utilidad social, sino que debe dar cuenta de la situación en que queda la autonomía individual.

En un planteamiento moderno de los fines del Derecho penal, en un Estado (social y) democrático de Derecho ${ }^{10}$, que define a tales fines en torno a la prevención y la garantía de la autonomía del individuo, la pena a imponer debe ser no sólo necesaria para la prevención, sino además justa, legítima en el caso concreto. La misión individualizadora-garantista asignada a la culpabilidad, se sigue imponiendo. Sólo que el Derecho penal de un Estado (social y) democrático de Derecho deberá renunciar a la pretensión de que sus valoraciones son objetiva y universalmente válidas, y fundamentar la culpabilidad en un supuesto distinto, compatible con un entendimiento verdaderamente pluralista y democrático de la sociedad.

\section{Diversas respuestas a la crisis de la idea de culpabilidad}

La crítica a la doctrina del "poder actuar de otro modo" caló bastante hondo en los cimientos de la teoría normativa de la culpabilidad. La búsqueda de un concepto material de culpabilidad alternativo al "poder actuar de otro modo", que supere sus deficiencias, es el rasgo común de la dogmática de la culpabilidad en el post-finalismo. Así, pues, los nuevos planteamientos intentan: superar el

\footnotetext{
${ }^{8}$ Kindhäuser, "Rechtstreue...”, pp. 729-730. Cfr. también Roxin, como en nota 8.

9 Roxin, como en nota 8. Sobre estas críticas, en general, cfr. también, García Arán, “Culpabilidad...”, pp. 81 y ss; Pérez Manzano, “Culpabilidad y prevención...”, pp. 95-96.

10 El paréntesis en que pongo el elemento "social" se explica porque los argumentos que se ofrecerán en torno a determinada fundamentación material de la culpabilidad, también pueden aplicarse a un modelo de Estado que, a diferencia del español (para cuyo ordenamiento jurídico se escribió originalmente parte de este trabajo), no se refiera explícitamente a su orientación "social" (como es el caso del chileno).
} 
déficit de verificabilidad empírica del concepto normativo de culpabilidad, eludir implicaciones moralizantes en el juicio de reprochabilidad o de culpabilidad y dar cuenta, también en el ámbito de la culpabilidad, de la fundamentación preventiva que se impone en la teoría penal. No faltarán quienes propongan la superación del concepto de culpabilidad, inútil para resolver los problemas dogmáticos que se imponen en materia de imputación subjetiva en el nuevo contexto teórico y político-criminal.

Con ello, la misión individualizadora-garantista que en algún momento de su evolución alcanzó la categoría sistemática culpabilidad, se ve sometida a nuevas tensiones. Toda una corriente, dentro de aquellas nuevas propuestas, pasa fundamentalmente por una generalización de la imputación subjetiva. Los conceptos de culpabilidad individualizadores suenan demasiado a irracionalidad científica, moralismo y retribución, en los sectores más progresistas de la doctrina juridicopenal, que son más sensibles a los aportes críticos de las ciencias sociales, orientan su elaboración dogmática a las necesidades de una Política criminal racional y secularizada y se muestran reacios a las fundamentaciones metafísicas e idealistas de la pena. Sin embargo, aunque parezca paradójico, la generalización, y la normativización preventiva de la categoría culpabilidad también se acomoda a las orientaciones político-criminales más conservadoras, temerosas ${ }^{11}$ de que a través de una ampliación de las posibilidades de exclusión de la culpabilidad el Derecho pierda eficacia preventivo-general, "se rompa el dique de contención" que la pena erige frente a las tendencias criminales de la población ${ }^{12}$.

En particular, la generalización del baremo utilizado en el juicio de culpabilidad se produce con la extensión del criterio del "hombre medio", ahora como respuesta a las críticas que niegan la verificabilidad empírica del "poder (individual) actuar de otro modo", mientras que su funcionalización deriva de la introducción de los fines de la pena como criterio de referencia del juicio normativo de culpabilidad, en la tesis de Roxin y sus seguidores, y luego, con la identificación entre culpabilidad y necesidad preventivo-general de pena, tesis sostenida, acaso en su versión más pura, por Jakobs ${ }^{13}$. Con todo, también se

\footnotetext{
11 Stratenwerth, "El futuro...", p. 124, califica de "temores imprecisamente fundados" a las objeciones preventivo-generales en contra de la ampliación de la capacidad exculpatoria del principio de culpabilidad.

12 Así, sostiene Maurach, criticando la doctrina del estado de necesidad, es más razonable castigar (incluso al "ciudadano medio") cuando la ley no puede desarrollar toda su fuerza motivadora en una situación individual, antes que "a causa del reconocimiento de un caso particular de ineficacia psíquica de la ley, romper el dique de contención que la ley erige frente a los deseos irreprimibles de miles" "Kritik der Notstandlehre" (1935), citado por Achenbach, "Historische...", p. 160

13 Ya en "Schuld und Prävention", pp. 8-9, Jakobs propone una concepción de la culpabilidad completamente funcional a la prevención general positiva: "la determinación de culpabilidad, en la aplicación del Derecho penal vigente, consiste en la fundamentación de la necesidad de una determinada medida de castigo, para confirmar la obligatoriedad del ordenamiento jurídico ante el ciudadano fiel al Derecho; la culpabilidad se fundamenta a través de la prevención general... y se mide según esta prevención".
} 
Couso - Culpabilidad y sujeto en la obra de Juan Bustos Ramírez

aprecia un tímido movimiento pendular, de regreso a la individualización del juicio de culpabilidad e incluso a la consideración de su sustrato "empírico", apoyado, aunque sólo parcialmente, por el propio Roxin, a quien en su momento se tuvo como fundador de la funcionalización de la culpabilidad a los fines de la pena ${ }^{14}$.

Pero también surgen en este período nuevas propuestas de entendimiento del concepto material de culpabilidad. El contexto es el fortalecimiento de la idea del carácter convencional de las prohibiciones penales, con lo cual la relación entre norma e individuo se problematiza, pues ya no se ve en la norma la expresión de una única racionalidad, moralidad o normalidad, ni se podrá ver en el autor del delito a un enfermo o un inmoral. La culpabilidad deberá responder a la pregunta, hasta ahora pasada por alto, de por qué debe el individuo motivarse por la norma. Ello abre nuevas posibilidades a un entendimiento individualizador de la culpabilidad. Pero también a una definición normativa de un concepto de persona fiel al derecho, como presupuesto básico del funcionamiento del sistema jurídico.

\section{Culpabilidad como exigibilidad social en Bustos Ramírez.}

Es precisamente en el contexto de la crisis de la teoría normativa de la culpabilidad que debe entenderse la concepción de Bustos Ramírez. Ella acentúa especialmente la dimensión sociopolítica de la responsabilidad penal, a la que concibe no como un poder individual, sino como una atribución del sistema social (al que Bustos Ramírez se refiere como "el sistema", abarcando también, al parecer, al Estado en el ejercicio del poder punitivo) que, sin embargo, debe respetar la autonomía ética de la persona y, por tanto, tiene que estar en consonancia con las condiciones que el propio sistema le ha ofrecido al sujeto para satisfacer sus necesidades.

\footnotetext{
${ }^{14}$ Cfr. la exposición crítica de Stratenwerth, "El futuro...", pp. 110-112. Digo "sólo parcialmente", porque, dentro de la categoría responsabilidad, construida por Roxin, concurren, tanto una concepto (reducido) de culpabilidad, como consideraciones preventivas, consideraciones que no sólo tendrán el carácter de límite de la culpabilidad sino que sustituyen (generalizándola) parte de lo que en un concepto más amplio y rico de culpabilidad (como "motivabilidad normal") sería imputación culpabilística individualizada (así, por ejemplo, el ámbito de la exigibilidad). A su vez. La culpabilidad en sentido reducido, se define tanto a partir de un elemento empírico -la "capacidad para reaccionar a las exigencias normativas" o "abordabilidad normativa, ("normative Ansprechbarkeit"), como de uno normativo -la atribución, a quien es "normativ ansprechbar", de la posibilidad de comportarse conforme a Derecho-. Pero aún así, la exigencia de un elemento empírico tiende a individualizar el juicio nuevamente, en contraste con lo que ocurre con una definición puramente normativa de la culpabilidad; cfr. Roxin “¿Qué queda...?, pp. 684-685 (siguiendo el planteamiento claramente empirista de Albrecht, "Unsicherheitszonen..."), y, "Strafrecht...", par. 19, nm. 39-42. Con todo, la forma en que después Roxin emplea al "segundo presupuesto" de la responsabilidad (la necesidad preventiva de pena) para resolver los casos en que la presencia del primero no es clara, hace dudar de que realmente el resultado sea individualizador y respetuoso de la base empírica del caso (véase Couso, "Fundamentos...”, pp. 232-233).
} 
El nivel de exigencias que el sistema puede imponer al sujeto, dependiente de las condiciones que le ha ofrecido al mismo, se traduce entonces en el criterio normativo de la exigibilidad, no sólo como uno de los elementos de la categoría sistemática culpabilidad, sino también como contenido material de toda la categoría.

\section{$\underline{\text { La exigibilidad social como contenido material de la culpabilidad }}$}

I. Según Bustos Ramírez, aunque la perspectiva liberoarbitrista tradicional no es adecuada para explicar la culpabilidad, este presupuesto de la punibilidad tiene también, como los anteriores (dentro de la secuencia de la teoría del delito), un "carácter cognoscitivo y garantizador"15. Por ello, aunque admite que los presupuestos de la pena deben tener una correspondencia con los fines de la pena, y que la definición preventiva de los segundos es incompatible con la mantención de unos presupuestos pensados para el retribucionismo, rechaza sin embargo la mera sustitución la culpabilidad por la necesidad preventiva de pena: "los fines de la pena no pueden sustituir sus presupuestos; hay allí un salto lógico evidente..." Es necesario precisar un contenido material garantista para la culpabilidad, como el que representa el bien jurídico para el injusto ${ }^{17}$.

Para ello, "es necesario partir no del individuo,...sino del individuo en sociedad. El hombre sólo puede ser comprendido en cuanto vive en sociedad"18, perspectiva en la cual la conducta desviada aparece como una construcción social y una atribución, sin una naturaleza propia distintiva: "falso es que la norma describa algo, lo que hace es imputar o asignar, la norma surge de una determinada estructura de poder, que no describe, sino que tiene por función imputar: designa delito (y delincuente); algo igual sucede con la expectativa; la expectativa también surge de alguien, de una estructura de poder que también tiene por función no describir, sino asignar" ${ }^{\prime 19}$. La norma, pues, como las expectativas de conducta que en ella se contienen, tiene un carácter contingente, político. En ese contexto, la conducta desviada y la racionalidad del autor expresada en ella no tienen una cualidad natural diferente de las demás conductas y racionalidades; todo lo más, son una conducta y una racionalidad que choca con las que políticamente se han impuesto como las debidas ${ }^{20}$.

Además, la racionalidad del sujeto (también la expresada en el delito) viene socialmente dada, no es un puro producto individual. En el delito, como en cualquier comportamiento social el hombre aparece "no como simple sujeto, sino como actor, esto es, que cumple determinado papel asignado, pero realizado por

\footnotetext{
${ }^{15}$ Cfr. Bustos Ramírez, "Manual...”, pp. 506-507.

16 Ibíd., p. 507.

17 Ibídem.

18 Bustos Ramírez, "Manual...", pp. 506 y 508.

${ }^{19}$ Ibíd., p. 509.

20 Como se verá, esto es especialmente claro en la concepción de Bustos Ramírez sobre la imputabilidad e inimputabilidad.
} 
él" ${ }^{\prime 2}$, del cual adquiere conciencia, pero también su conciencia surge del proceso social, de su relación social. Así, si bien el hombre, como actor dentro del proceso social, puede responder de su actuación, en razón de la conciencia concreta de su papel, se plantea también la responsabilidad de la sociedad, tanto por el papel que le ha asignado al hombre como por los controles que le ha impuesto (incluida la pena): "la sociedad responde también por esa conciencia lograda por el hombre",22.

En conclusión, "culpabilidad es responsabilidad”, según Bustos Ramírez, y no reproche ni poder actuar de otra manera. El hombre responde por su comportamiento, por la conciencia de él: ése es el fundamento y límite de la reacción social; pero por esa conciencia, dada socialmente, responde también la sociedad toda. ${ }^{23}$

En este contexto, y como una dimensión de "protección de la autonomía ética de la persona", la cuestión a la que responde la culpabilidad es "qué puede exigir el sistema al sujeto concreto como respuesta al conflicto social"; el criterio material de culpabilidad de la "exigibilidad social". Y el baremo de la exigibilidad se encuentra en las condiciones impuestas por el sistema al sujeto, de modo que "el sistema no puede exigir si no ha proporcionado o no se dan las condiciones necesarias para que la persona pueda asumir una tarea determinada (exigida por el sistema)" ${ }^{\prime 2}$.

La exigibilidad se convierte así en "principio fundamentador, garantista y deslegitimador de la intervención punitiva del Estado" "25. El problema a debatir es "qué respuesta determinada le puede exigir el sistema a una persona determinada respecto a la satisfacción de sus necesidades, dentro de una relación social concreta" ${ }^{26}$. Eso significa no seguir poniendo el acento, como la teoría tradicional de la culpabilidad, en el individuo, su bondad o maldad, su determinación o no, "sino en una interrelación entre persona, reconociendo su carácter de tal [capaz de racionalidad, de conciencia de su papel, es decir, responsable], y sistema, con lo cual se reconoce al mismo tiempo la subordinación de éste a la persona"27.

La exigibilidad se basa, entonces, en que: i) el sujeto es responsable porque adquiere conciencia de su papel social y realiza ese papel, porque es un ser racional, capaz de una determinada racionalidad, y, ii) en la situación social concreta puede pedírsele a ese sujeto concreto que resuelva sus necesidades sociales en forma alternativa al delito. El primer presupuesto se da siempre, según Bustos Ramírez, y forma parte del concepto de sujeto y de su dignidad; el segundo, no siempre, y es

\footnotetext{
${ }^{21}$ Bustos Ramírez, "Manual...”, p. 510.

22 Ibídem.

${ }^{23}$ Ibíd., p. 511.

${ }^{24}$ Ibíd., p. 512.

${ }^{25}$ Ibíd., pp. 512-513.

${ }^{26}$ Ibíd., p. 513.

${ }^{27}$ Ibídem.
} 
el centro y fundamento del juicio de culpabilidad.

II. En su estudio particular sobre la imputabilidad, Bustos Ramírez profundiza su concepción sobre el sujeto responsable y sobre las condiciones bajo las cuales puede efectivamente exigírsele responder por su contradicción con la racionalidad hegemónica.

En un conocido trabajo ${ }^{28}$, Bustos Ramírez desarrolla para el ámbito de la imputabilidad su concepción crítica acerca del carácter político-hegemónico de las normas juridicopenales y del carácter definitorio del delito. La teoría penal tanto clásica como neoclásica han ignorado esa realidad, y la definición de inimputabilidad sigue basándose en la idea de la irracionalidad (incapacidad de comprender la ilicitud del hecho y de actuar conforme a ella) o de la enfermedad (entendida a priori también como peligrosidad) del delincuente ${ }^{29}$.

Ello ya puede objetarse "desde un punto de vista estrictamente éticofilosófico", contraponiendo a la pretensión de una ética objetiva una ética subjetiva, en la que, desde el punto de vista del individuo, los valores aparecen como relativos ${ }^{30}$. Pero Bustos Ramírez intenta además una crítica sobre la base de la teoría de las subculturas y de la psiquiatría alternativa.

Su idea guía es la negación de la existencia de una racionalidad única que permita considerar "incapaces" a quienes tienen una racionalidad diversa a la hegemónica; la inimputabilidad tiene una dimensión política.

De su estudio de la teoría de las subculturas, en el que Bustos Ramírez se ocupa también del fenómeno de la coexistencia de culturas en un mismo espacio físico, este autor concluye que el individuo se encuentra situado en diferentes ámbitos culturales, y que, por tanto, "desde el punto de vista existencial el problema de la imputabilidad es mucho más complejo de como lo han planteado las dos teorías tradicionales (la clásica y la positiva)... por tanto, el primer nivel de la imputabilidad desde un punto de vista existencial sólo podría implicar la asignación de un individuo a uno de los órdenes culturales o racionales dados y nada más" ${ }^{\prime 31}$.

En segundo lugar Bustos Ramírez acomete la cuestión existencial del individuo mismo como unidad psicosocial, que es el punto de vista de la siquiatría alternativa $^{32}$. De los planteamientos de la siquiatría alternativa concluye Bustos Ramírez que la locura ha de entenderse "como un fenómeno social, como una

\footnotetext{
28 "Revisión crítica de la imputabilidad a la luz de las teorías de las subculturas y la siquiatría alternativa" (1982; cit. "Revisión crítica...”).

29 "Revisión crítica...", p. 192; cfr. también el mismo, "Imputabilidad y edad penal”, p. 473.

30 "Revisión crítica...”, pp. 192-193; cfr. también, el mismo, "Manual...", pp. 518-519.

31 "Revisión crítica...", p. 197.

32 Ibíd., p. 198.
} 
contradicción que puede darse en cualquier tipo de sociedad y frente a la cual reacciona dicha sociedad, lo que es además determinante para el desarrollo futuro de la locura. La locura significa entonces un conflicto entre las normas y valores de un sistema social determinado, en definitiva de la verdad del sistema social con la verdad que expresa el loco"33. La posición tradicional es una respuesta represiva, de control social frente al loco; "la locura como la delincuencia es un problema político" ${ }^{34}$.

Como resultado de todo ello, afirma Bustos Ramírez, "no se puede decir respecto de un determinado sujeto que carezca de la capacidad de conocimiento existencial y de obrar de acuerdo a él; ello presupondría la creencia de que existencialmente existe un sólo orden de valores y una sola verdad, lo cual es falso. El sujeto puede tener su propio orden de valores y su verdad, tanto en consideración a su mundo cultural (subcultural o contracultural) como también en virtud de una forma conflictiva propia de enfrentarse al sistema social en que vive.... ${ }^{35}$. Como se desprende de la teoría de las subculturas delictuales y de la siquiatría alternativa "la imputabilidad no se puede concebir como un juicio de invalidación de un sujeto como el que "no es capaz de", sino simplemente como un juicio de asignación a un determinado orden racional o a una determinada racionalidad", siendo necesario analizar un "segundo nivel, que es el juicio político valorativo que implica la imputabilidad"36.

Bustos Ramírez analiza el juicio de imputabilidad desde el modelo de "Estado social y democrático de Derecho" acogido por la Constitución Española $^{37}$. En un primer nivel la imputabilidad, entendida como la capacidad de racionalidad que todo sujeto tiene, se traduce en el reconocimiento de un orden pluralista en que "cualquier persona puede pertenecer a la cultura que ella elija, al orden racional que estime más adecuado... en principio, ningún orden racional o cultural o grupal puede ser discriminado por un Estado de Derecho, ya que ello significa la destrucción de sus propias bases al negar al individuo"38.

Pero el juicio de imputabilidad en un Estado de Derecho significa, sin duda, más que eso; "implica además un segundo nivel, que es el reconocimiento de un orden racional hegemónico dentro del Estado y que constituye la base orgánica del mismo", y cualquier individuo es "valorado" desde la perspectiva de la contradicción con los valores de ese orden ${ }^{39}$. Pero tal enjuiciamiento, para no transgredir el primer nivel (pluralismo cultural y de racionalidades), "no puede juzgar el grupo u orden en sí, sino sólo los hechos llevados a cabo, los injustos,

\footnotetext{
33 Ibíd., p. 205.

${ }^{34}$ Ibíd., pp. 205-206.

35 Ibíd., p. 206; cfr. también, el mismo, "Manual...", p. 520.

36 "Revisión crítica...", como en nota anterior.

${ }^{37}$ Ibíd., pp. 206-207.

${ }^{38}$ Ibíd., pp. 208-209.

${ }^{39}$ Ibíd., p. 208.
} 
cometidos, es decir el principio de la responsabilidad por el hecho resulta insoslayable para el segundo nivel en que opera el juicio de imputabilidad... Luego en modo alguno es un juicio valorativo absoluto, sino eminentemente práctico, relativo, de carácter político estatal y jurídico, luego también cambiante, revisable críticamente y, en la medida de una profundización del Estado de Derecho, progresivamente más abierto y flexible" ${ }^{\text {"40 }}$.

En seguida, ese "juicio de compatibilidad o incompatibilidad de la racionalidad del individuo con la racionalidad hegemónica del sistema" presupone además el respeto de la dignidad humana, por lo que "requiere como base fáctica del juicio la existencia de una comunicación entre los órdenes racionales existentes. Si no hay tal comunicación no es posible pasar al segundo nivel, pues en el fondo implicaría una transgresión del primero, es decir, una discriminación". Con ello, Bustos Ramírez quiere excluir la imputabilidad por ejemplo de indígenas que no han entrado en contacto o viven en marginación total respecto del orden hegemónico, de los infantes, de los sordomudos, y de los "locos"

Pero el problema de más difícil solución se presenta cuando sí ha existido comunicación entre los órdenes racionales, como en el caso de ciertos grupos culturales distintos del hegemónico, que han vivido un cierto tiempo conjuntamente con él, así como en el caso de los jóvenes y de ciertas "locuras". En estos casos la solución depende de "la amplitud democrática alcanzada por el Estado", en lo que está involucrado también el efectivo respeto del "primer nivel" del juicio de imputabilidad. ${ }^{42}$

En definitiva, la imputabilidad en el primer nivel es "un reconocimiento de la existencia de varias racionalidades, que no son falsas ni verdaderas sino existentes"43. En el segundo nivel, la imputabilidad es el "juicio de incompatibilidad de la racionalidad expresada en un acto preciso del individuo con la del orden hegemónico", es un juicio negativo formulado desde el sistema, plasmado en el orden jurídico establecido ${ }^{44}$. Por tanto el problema de la imputabilidad o inimputabilidad es un hecho político, y puede preverse que "una profundización democrática del Estado podrá posibilitar la compatibilidad de todos los órdenes racionales existentes, con lo cual habrá desaparecido la imputabilidad como concepto y con ello el delincuente...."45.

En cambio, en la inimputabilidad no se puede declarar la incompatibilidad de racionalidades, pues detrás de todo caso de inimputabilidad hay problemas de comunicación entre racionalidades: "La inimputabilidad implica reconocer

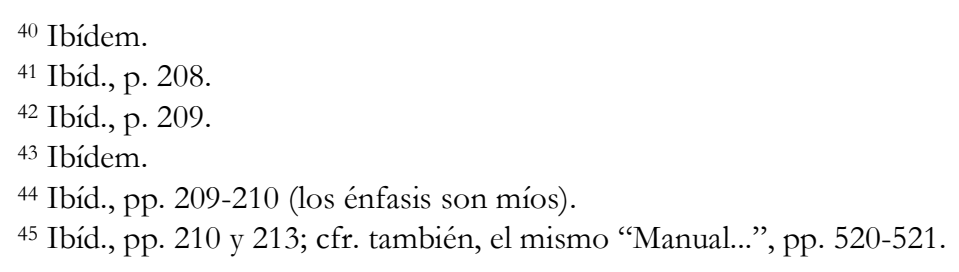


problemas de carácter general en los procesos de comunicación en un sistema y de ahí el juicio de compatibilidad, porque no es posible de modo general exigir una respuesta determinada"46. En la imputabilidad, en cambio, el juicio de incompatibilidad implica "que no se dan problemas de carácter general en los procesos de comunicación y, por tanto, que en principio se puede exigir de modo general una respuesta determinada a esas personas, sin perjuicio entonces que pueda haber problemas de carácter específico en los procesos de comunicación”" ${ }^{47}$.

Además, aclara que la imputabilidad, como la culpabilidad en general, se refiere a la exigibilidad social: "La cuestión de la imputabilidad e inimputabilidad es la resolución de la exigibilidad e inexigibilidad a nivel general respecto del comportamiento de una persona; la inimputabilidad implica inexigibilidad por parte del sistema, la imputabilidad, en cambio, la exigibilidad por parte del sistema" $"$.

En otro trabajo ${ }^{49}$ Bustos Ramírez traduce la idea de los diversos niveles de la imputabilidad, especialmente para el ámbito del Derecho penal de menores, en la distinción entre una responsabilidad penal general y una responsabilidad penal criminal. La primera "está definida en su contenido por el hecho de una intervención coactiva por parte del Estado sobre los derechos básicos del sujeto y que obliga por tanto a la consideración de todas las garantías desarrolladas para evitar el abuso y arbitrariedad del Estado...", y dentro de ella hay que considerar la responsabilidad penal administrativa, y la responsabilidad penal de los inimputables, a quienes se les aplican determinadas sanciones o medidas ${ }^{50}$. Los principios garantistas básicos son la responsabilidad por el hecho y la legalidad de los delitos (o, en general, hechos infractores) y las penas. La responsabilidad penal criminal es la de los imputables (en el segundo nivel).

\section{Valoración y crítica}

I. El planteamiento de Bustos Ramírez pone de relieve, en síntesis, los siguientes elementos para la búsqueda de un fundamento material de la culpabilidad, tras la crisis de la fundamentación retribucionista basado en la reprochabilidad individual del sujeto que cometió el injusto pese a que "podía actuar de otro modo":

$1^{\circ}$ El énfasis en el carácter contingente y meramente positivo de las valoraciones en que se basan las normas penales, que no pueden reclamar para sí una racionalidad, moralidad y corrección objetivas, pre-jurídicas o pre-políticas.

\footnotetext{
${ }^{46}$ Ibíd., p. 520.

47 Ibídem.

48 Ibídem.

49 "Imputabilidad y edad penal", pp. 473 y ss.

${ }^{50}$ Ibíd., p. 473-474.
} 
$2^{\circ}$ La dimensión de dominación hegemónica que se oculta en muchas de las decisiones incriminatorias, que deja en una posición desventajosa a los grupos minoritarios o excluidos (la desventaja de tener que someterse a una racionalidad hegemónica, diversa de la propia).

$3^{\circ}$ La dimensión social y no meramente individual- de la producción de la conducta criminal, surgida de la interacción entre las condiciones que el sistema social entrega o deja de entregar al individuo para que éste cumpla con las exigencias del ordenamiento jurídico hegemónico (que configuran el "papel" asignado al individuo), y la forma en que el sujeto desempeña concretamente ese papel asignado.

$4^{\circ}$ Los problemas de comunicación que surgen entre la racionalidad hegemónica y la racionalidad de los individuos o grupos marginales, particularmente en los casos de inimputabilidad (del "segundo nivel").

Teniendo en cuenta esos elementos, la culpabilidad del individuo depende de las condiciones entregadas por el sistema social para cumplir su papel y de las condiciones/defectos de comunicación entre la racionalidad hegemónica y la del individuo o grupo marginal.

De esa forma, la concepción de Bustos Ramírez sobre la culpabilidad subraya convenientemente la dimensión política del juicio de culpabilidad. Esa dimensión política es destacada en la actualidad -si bien en otro sentidoespecialmente por planteamientos desarrollados a partir de la teoría del discurso, como los de Kindhäuser y Günther. Por eso, me parece de especial interés intentar una comparación, en forma algo preliminar y resumida, entre la concepción de Bustos y las de estos autores, identificando qué elementos de "la dimensión política" del juicio de culpabilidad son tenidas en cuenta en sus diversas concepciones. Tras ese ejercicio me mueve el propósito de señalar que ambas concepciones son insuficientes, precisamente en lo que desconocen de la otra. Por mi parte, pretendo que mi propia concepción ${ }^{51}$, recoge elementos de cada una de ellas que son complementarios y ofrecen un fundamento más consistente al juicio de culpabilidad.

II. En la concepción de Bustos Ramírez el elemento central de la dimensión política de la culpabilidad se ubica en la co-construcción social de la conducta criminal, tanto por la definición hegemónica de las prohibiciones penales (que expresan la "racionalidad" dominante) como por la medida en que el sistema social-estatal ofrece o deja de ofrecer al individuo condiciones suficientes para que éste pueda responder al papel que se le ha asignado.

En cambio, y éste es en mi opinión el principal déficit en su concepto material de culpabilidad, Bustos Ramírez no llega a considerar la dimensión

\footnotetext{
${ }^{51}$ Desarrollada en profundidad en "Fundamentos...", passim.
} 
política que subyace a los problemas de comunicación entre el autor y la norma (problemas de comunicación entre racionalidad hegemónica y racionalidad del individuo o grupo marginal), sino que trata esta cuestión desde una perspectiva puramente individual, es decir, dando relevancia únicamente al déficit en la capacidad del autor de acceder a la racionalidad hegemónica (sea debido a un problema "de carácter general", sea "de carácter específico").

Para decirlo de otra manera, retomando el planteamiento de Bustos Ramírez sobre la imputabilidad: si el autor no logra acceder a la racionalidad hegemónica expresada en la norma, el ordenamiento debe tolerar esa imposibilidad, declarándolo inimputable; si el autor, en cambio, porque ha tenido suficiente contacto con una racionalidad hegemónica, aún cuando no sea la suya, logra comprenderla ("comunicarse" con ella), entonces es imputable. Es decir, la imputabilidad, y la culpabilidad en general, no dependen en absoluto de la calidad democrática de los procedimientos de producción de la razón hegemónica, sino sólo de las capacidades individuales del sujeto de acceder a sus contenidos, es decir, de comprenderlos, por más alejados que estén de su propia racionalidad, por más hegemónico que sea el poder que los construyó y que le asignó el papel de tener que conformarse a ellos desde su posición de (sub)cultura marginal.

De esa manera, la concepción de la culpabilidad de Bustos Ramírez es capaz de hacerse cargo de sólo de una de dos dimensiones de la autonomía que el concepto material de culpabilidad debería preservar: la garantía de que al sujeto no se le exigirá lo que no puede, a saber, cumplir con aquellas exigencias de la norma hegemónica para las cuales el sistema social no le ha entregado lo suficiente. Ello se expresa en la práctica, en que no se le exigirá cumplir con normas cuya racionalidad no puede entender por falta de acceso cognitivo a la misma (por ejemplo, cuando no ha existido comunicación entre los diversos órdenes racionales -piénsese en comunidades indígenas muy alejadas geográfica y/o culturalmente- o cuando sufre de un "problema de carácter específico"), ni con normas que no puede cumplir por falta de condiciones materiales o socioculturales para hacer frente a las exigencias que ellas le imponen (piénsese en el caso de los menores de edad que aún no han recibido del Estado ni siquiera la instrucción básica -ejemplo empleado por Bustos Ramírez, para fijar en 14 años la edad mínima de aplicación del derecho penal de menores-). De estas dos formas de incapacidad o imposibilidad, en realidad, sólo la segunda se ubica en un plano político.

En cambio, su concepción de la culpabilidad no es capaz de asegurar otra dimensión de la autonomía: la garantía de que al sujeto no se le someterá a reglas heterónomas, lo que se expresa en la condición de que las reglas cuyo cumplimiento se le exige no sean las de una razón hegemónica frente a la cual el sujeto tiene la posición de un excluido, sino reglas que en algún sentido políticamente significativo, pueden considerarse sus propias reglas.

Así, si bien el criterio material de la "exigibilidad social" incorpora una 
dimensión política al juicio de culpabilidad, esa exigibilidad depende de lo que el sistema ha dado al individuo, más bien en su dimensión de "Estado social" (o "Estado prestador") -que crea un ámbito material de igualdad- que de "Estado democrático" -que permite al individuo participar en la generación de las normas que lo obligarán-. En ese marco, habría que deducir del criterio de la "responsabilidad social" de Bustos Ramírez, que un Estado que ofrece condiciones materiales a sus ciudadanos suficientes para contar con una base de igualdad (por ejemplo, educación gratuita de calidad para todos los niños hasta los 14 ó 18 años), puede exigirles respeto a sus normas, con independencia de si les ofrece o no espacios democráticos reales para participar del proceso nomogenético. Con todo, también debe advertirse que en esta definición del fundamento material de la culpabilidad, siquiera de una forma indirecta, sí tiene relevancia aquella segunda dimensión de la autonomía individual y de la relación política entre autor y norma, pues también es posible considerar en alguna medida como propias, en un sentido político, a aquellas normas que protegen bienes en cuyo disfrute material el individuo participa y respecto de las cuales performativamente se define como autor al reclamar del ordenamiento jurídico esa protección ${ }^{52}$. Pero, aún así, ello sólo fundamentaría la responsabilidad del sujeto excluido (del proceso nomogenético) en relación con las normas que de manera más evidente le interesan también a él, y no en cambio en relación con muchas otras que protegen intereses que le son del todo ajenos.

III. Estas objeciones, con todo, podrían ser contestadas desde una perspectiva distinta, que no asuma el presupuesto liberal que subyace a ellas, a saber, que las normas deben ser aceptables desde una perspectiva racional-individual. Tal sería el caso de una justificación de la vinculación del sujeto a la norma construida desde la filosofía política del comunitarismo ${ }^{53}$. De hecho, el punto de partida de teoría del conocimiento del comunitarismo es el mismo que asume Bustos Ramírez: el individuo no es un ser racional ahistórico y atomizado, sino un "hijo de una sociedad concreta en una época concreta", de modo que su identidad no es anterior a la sociedad sino que es constituida por ella ${ }^{54}$. La consecuencia filosóficopolítica que de ello extrae el comunitarismo, es que la fundación de la identidad del Yo individual por medio de la sociedad "fundamenta una compenetración entre individuo y sociedad en el sentido de una comunidad, de la que resulta el deber de cada uno de promover el bien común", siempre, claro está que se trate de una democracia ${ }^{55}$. El individuo, en ese caso, no es visto como un particular sino que, en cierto modo, nace en su rol de ciudadano ${ }^{56}$, de modo que no hay contradicción

\footnotetext{
52 Couso, “Fundamentos...”, pp. 419-421.

${ }^{53}$ Cfr. el interesante análisis del fundamento de legitimidad de las normas en el comunitarismo, y del concepto de culpabilidad que deriva de él, ofrecido por Kindhäuser, "Rechtstreue...", pp. 709711; sobre ello, un resumen, infra, en este capítulo, 9.1.IV.

${ }^{54} \mathrm{Cfr}$. Kindhäuser, como en nota anterior.

55 Pues "sólo en democracia la participación en el poder se traduce, por sobre todo, en obligación de promover el bien de todos"; sobre esto, y el texto principal, cfr. Kindhäuser, "Rechtstreue...", p. 710.

${ }^{56}$ Kindhäuser, ibíd., pp. 710-711.
} 
entre su autonomía ética individual y la ética social democrática. Con la lesión normativa el ciudadano no defrauda expectativas heterónomas, sino que traiciona la lealtad que debe a la sociedad y al Derecho, abandona la comunidad ${ }^{57}$.

Ello permitiría responder por qué debe el que puede aquello que la sociedad le exige. Porque todo ciudadano está obligado a realizar el bien común, está obligado a la solidaridad. Y ello no contradice su conciencia individual, pues su conciencia viene dada por la sociedad, e impregnada en su propia concepción del deber, de lo ético, por aquellos consensos fundamentales de la sociedad acerca del deber y lo ético; no existe una conciencia individual previa a la sociedad que pueda ser contradicha por lo que dicta la conciencia social democráticamente fundada. Dada esta relación de continuidad entre conciencia individual y conciencia (democrática) social, la única garantía de la conciencia individual necesaria es asegurar que al individuo no se le exija más que lo que puede, y ello depende de lo que la propia sociedad le ha dado, del papel que le ha asignado.

Esa sería una posible reconstrucción del concepto material de culpabilidad en Bustos Ramírez, que le liberaría de la necesidad de justificar especialmente el deber individual de cumplir con la exigencia social, que está dentro de sus capacidades individuales. Sin embargo, fuera de ciertos indicios en el tratamiento del error de prohibición, que por lo demás pueden interpretarse desde otras fuentes teóricas, su concepción no parece fácilmente conciliable con el comunitarismo. Pues Bustos Ramírez, al tratar de la imputabilidad, rechaza frontalmente (de hecho ya lo hizo en general en materia de culpabilidad) la existencia de valores o verdades absolutas en una sociedad pluralista, siendo que el comunitarismo demanda, en cierto sentido, una validez racional general de las valoraciones surgidas del consenso democrático ${ }^{58}$. Por lo demás, es claro que una definición de la culpabilidad a partir del comunitarismo tiene más problemas que un enfoque basado en la teoría del discurso para cumplir con la misión que Bustos Ramírez quiere preservar para aquella categoría de delito, de garantizar la autonomía ética de la persona. Pues en el marco del comunitarismo, la afirmación del deber individual de cumplimiento de las exigencias de la comunidad, por el mero hecho de contarse con la capacidad de hacerlo, se realiza al precio de identificar la conciencia ética individual con la conciencia ética social surgida de la democracia de mayorías.

Con todo lo anterior habría que concluir que la responsabilidad del sujeto por lo que la sociedad le exige en atención al papel sociopolítico que le asignó es un criterio de culpabilidad material insuficiente para quien no abrace el comunitarismo. Fuera del marco teórico del comunitarismo, en cambio, hay que ir más allá de la pretensión

\footnotetext{
${ }^{57}$ Ibíd., p. 711.

${ }^{58}$ Cfr. "Manual...", p. 518. Sin embargo, la duda vuelve a surgir cuando Bustos Ramírez afirma ("Revisión crítica...”, p. 208) que en un Estado social y democrático de Derecho la imputabilidad implica que todo individuo es valorado desde la perspectiva de los valores de la racionalidad hegemónica del Estado.
} 
social de exigir algo al individuo; es necesario establecer alguna vinculación interna, de base racional-individual, entre el individuo y la norma de conducta social expresada en la prohibición penal ${ }^{59}$.

IV. Las concepciones sobre el fundamento material de la culpabilidad de Kindhäuser y Günther, por su parte, apoyadas en la teoría del discurso, enfatizan correctamente en mi opinión la dimensión política de la génesis democrática y participativa de las normas -definida como autonomía política, o autonomía deliberativa del ciudadano-, como condición de posibilidad de una vinculación autónoma (no heterónoma) del ciudadano con las prohibiciones penales. Pero, como haré notar, a partir de una definición abstracta del papel del ciudadano como autor racional de la norma, tienden a ignorar -en mayor medida Kindhäuser, en menor medida Günther, pero definitivamente también- las condiciones reales de autonomía política, que exigen, en el planteamiento habermasiano, la vigencia previa de un sistema de derechos, incluyendo también los derechos de contenido económico-social, a los que no tienen acceso los grupos marginados socialmente.

\section{Autonomía comunicativa y culpabilidad en Kindhäuser}

De la concepción de Kindhäuser ${ }^{60}$ hay que partir destacando su insistencia en que la culpabilidad material debe ser capaz de responder a la cuestión de la legitimidad de la pena, siempre que con esto se entienda que la culpabilidad "pone en apuros" a la pena, imponiéndole requisitos materiales de legitimidad, y no en el sentido de que la culpabilidad reviste a la pena de legitimidad, sin que nada cambie realmente. Pero creo que, a pesar del potencial de su teoría, Kindhäuser corre el peligro de quedarse en este segundo sentido de la palabra "legitimación",61.

Desde luego, también merece destacarse que Kindhäuser, de la mano de la filosofía del Derecho de Habermas, renueve el discurso sobre legitimidad en materia de Derecho penal y de culpabilidad. De acuerdo con el planteamiento de Habermas, para que el Derecho cumpla con su misión de integración social todavía necesita incorporar otra dimensión de la validez: la legitimidad. En la filosofía del Derecho de Habermas, las disposiciones del poder, en que consisten las normas jurídicas positivas, "sólo pueden resultar a la larga eficaces... si tienen a

\footnotetext{
${ }^{59}$ Esta perspectiva, presente ya en la versión de Muñoz Conde de la concepción de la culpabilidad como motivabilidad (cfr. Couso, "Fundamentos...", Capt. tercero, 4.2.) y desarrollada sobre nuevas bases teóricas por Kindhäuser (aunque con resultados menos satisfactorios; cfr. infra), es la que asumo al esbozar una "propia concepción" (en Couso, "Fundamentos...", Capt. cuarto, especialmente 4.2 a 4.7, y, analizando consecuencias dogmáticas y político-criminales, en Capt. quinto).

${ }^{60}$ Para un análisis crítico más detallado de su concepción, véase Couso, "Fundamentos...”, pp. 246 y ss. También las referencias de Günther, "Schuld...", pp. 245 y ss.

${ }^{61}$ Con ello no pretendo ignorar que si la pena impuesta en concreto cumple con las exigencias de legitimación que le formula la culpabilidad, también se legitima en el segundo sentido, pero sólo desde el punto de vista de la culpabilidad, pudiendo ser ilegítima por otras razones; cfr. sobre ello, Couso, "Fundamentos...", Capt. primero, 3.
} 
su favor la presunción de ser determinaciones de la razón" ${ }^{\text {26 }}$.

Ahora bien, según Habermas, el Derecho positivo moderno debe resolver esa necesidad, no ya con la identificación entre norma jurídica y racionalidad objetiva, sino mediante un ensamble (Verscbränkung) entre forma jurídica y principio discursivo ${ }^{63}$, entre Derecho positivo y legitimidad comunicativa, ensamble que dé por resultado que el individuo pueda considerar legítima a la norma ya por el sólo hecho de su vigencia positiva, lo que a su vez exige que las condiciones materiales que la convirtieron en Derecho positivo hagan posible que ese (todo) individuo se pueda sentir autor racional de la misma ${ }^{64}$. Esas condiciones no son otras que la autonomía comunicativa ${ }^{65}$, es decir, la más plena vigencia de los derechos fundamentales de la esfera pública y privada, que hacen materialmente posible que todos hagan valer su punto de vista en el proceso discursivo (comunicación orientada al entendimiento ${ }^{60}$ ) de creación de las normas, y que el resultado de ese proceso exprese el punto de vista del bien común ${ }^{67}$.

Dicho en forma más sencilla, para Habermas, la legitimidad de las normas depende, no de una racionalidad objetiva de contenido, que no tienen, sino de que fueron creadas a través de un procedimiento democrático sin distorsiones. Ello significa para la culpabilidad, concluye Kindhäuser, que hay culpabilidad material, es decir, puede afirmarse que el autor debió motivarse por la norma, si concretamente él goza de autonomía comunicativa, esto es si él ocupa una posición que le permite intervenir en ese procedimiento democrático sin distorsiones.

Pero eso no explica el merecimiento de pena, ni la expresión de "decepción" que Kindhäuser quiere seguir reconociendo en el juicio de culpabilidad. Para ello es necesaria una explicación adicional, que se haga cargo de la incapacidad del derecho positivo de ofrecer al individuo razones intrínsecas a favor de su respeto. Según Kindhäuser, si la culpabilidad material tuviese que referirse a la racionalidad individual o a la solidaridad comunitaria entonces no sería posible afirmarla respecto de normas que no pueden garantizar su justicia; es decir, no habría culpabilidad material, pues ni la racionalidad ni la virtud son componentes del Derecho. Sin embargo, si la culpabilidad se refiere a los componentes del Derecho, esto es, a la autonomía comunicativa y a la lealtad comunicativa, entonces sí puede hablarse de culpabilidad material ${ }^{68}$. Y se construye así.

\footnotetext{
62 Jiménez Redondo, “Estudio preliminar...”, p. 88.

${ }^{63}$ Ibíd., pp. 89 y 93-94.

${ }^{64}$ Cfr. Habermas, "Faktizität...", pp. 51-52.

${ }^{65}$ Cfr. Couso, "Fundamentos...”, Capt. Tercero, 9.3.I.

${ }^{66}$ Ibíd., Capt. tercero, 9.2.II.

${ }^{67}$ Habermas, "Faktizität...", pp. 109 y ss.; cfr. sobre ello también, García Amado, "La filosofía...”, pp. 238-239.

${ }^{68}$ Kindhäuser, “Rechtstreue...”, p. 725.
} 
Antes del entendimiento no hay derecho alguno; la única forma de determinar el campo de acción del particular son las normas surgidas en el proceso de entendimiento, que aparecen dotadas de racionalidad provisional; estas normas sólo pueden ser cambiadas legítimamente dentro de los límites de la lealtad comunicativa. Con la infracción normativa "el autor niega el entendimiento que subyace a la norma y con ello la autonomía comunicativa de los partícipes (en dicho entendimiento)", aún con independencia de que él considere la norma irracional o injusta, pues "no su racionalidad, sino la lealtad comunicativa frente a la autonomía de los demás, es lo que vincula al autor a la norma". Por lo tanto "resulta natural denominar a la lealtad comunicativa así descrita, sobre la que se basa el efecto vinculante legitimante de las normas democráticas, fidelidad al Derecho" " Así, concluye Kindhäuser, "culpabilidad en el Estado democrático de Derecho es, en una formulación muy general, una acción que expresa un déficit de fidelidad al derecho -esto es, de lealtad comunicativa, que posibilita cualquier forma jurídica de entendimiento-" ${ }^{\prime 70}$.

Sin perjuicio de sus virtudes, mencionadas más arriba, la concepción de Kindhäuser sobre la culpabilidad material se hace acreedora de una importante objeción, por incurrir en una recepción muy formal y abstracta de la concepción habermasiana sobre la autonomía comunicativa del individuo, como condición de legitimidad de las normas.

Es evidente que el modelo de la democracia sin distorsiones ${ }^{71}$ no es algo que exista en el mundo que conocemos. Sin embargo, hay sistemas políticos y jurídicos que se acercan más que otros a ese modelo, y, sobre todo, hay individuos y grupos respecto de los cuales se satisfacen mejor los presupuestos de la autonomía comunicativa que respecto de otros. Por ello el modelo de la democracia sin distorsiones (el principio discursivo llevado al plano social y político) debe servir fundamentalmente para la crítica y la reforma del sistema político y jurídico que conocemos $^{72}$.

Pero Kindhäuser parte sencillamente de la base de que la autonomía comunicativa es una realidad, convirtiendo de esa manera lo que ha sido pensado como un principio crítico, en una definición normativa. Con ello pasa por alto que la buena parte de los individuos condenados por un delito se encuentra en gran medida socialmente marginada, y no ha contado con poder político y social real para participar en el proceso de génesis normativa; las normas son para ellos, en gran medida, mandatos heterónomos. Así, el individuo termina debiendo fidelidad al Derecho en base a ciertas facultades (comunicativas, es decir, políticas) que se le

\footnotetext{
${ }^{69}$ Ibíd., p. 725 (el énfasis es mío).

${ }^{70}$ Ibíd., pp. 725-726.

71 Que se remonta al modelo de la "comunidad de diálogo libre de dominación” en el que Habermas basa su filosofía del conocimiento; cfr. sobre ello, Hassemer, "Fundamentos...”, pp. 163166.

${ }^{72}$ En ese sentido Hassemer, como en nota anterior, p. 166.
} 
Couso - Culpabilidad y sujeto en la obra de Juan Bustos Ramírez

reconocen idealmente, pero de las que no dispone en la práctica.

Esta objeción no pretende desacreditar el potencial crítico de la concepción de legitimidad normativa de Habermas, y de su aprovechamiento para el problema de la culpabilidad por Kindhäuser. Pero sí quiero recalcar que la omisión, por parte de Kindhäuser, de toda referencia a las condiciones reales de la autonomía comunicativa en los sistemas políticos y penales histórico-contingentes, acarrea el peligro de hacer de su discurso, como he señalado, no un desafío para que la pena supere mayores estándares de legitimidad, sino una legitimación ideológica del sistema vigente.

Así pues, una fundamentación material de la culpabilidad sobre esta nueva base teórica propuesta por Kindhäuser debería hacerse más "histórica", debería tener en cuenta los déficit de realización del principio discursivo, y debería poner el acento, con ello, en que la relación interna entre individuo y norma, la motivabilidad por las normas, depende de la posición real socio-política que le ha sido asignada al individuo dentro del proceso de diálogo social y político acerca de las normas juridicopenales.

Precisamente esa perspectiva histórico-crítica de las condiciones reales de participación de individuos y grupos en un sistema político con importantes distorsiones -al extremo de constituirse respecto de no pocos, como un poder hegemónico excluyente-, es aportada por la concepción de Bustos Ramírez, que rechaza la exigibilidad cuando, más allá de la ciudadanía formal, el sujeto no ha recibido del sistema las condiciones (también materiales) necesarias para desempeñar el papel que le ha sido históricamente (y no sólo normativamente) asignado $^{73}$.

Debido a aquellas limitaciones en el horizonte de condiciones de la autonomía comunicativa tenidas en cuenta por Kindhäuser ${ }^{74}$, sus consecuencias prácticas en la reconstrucción de la categoría de culpabilidad terminan siendo casi mínimas, comparadas con las que su fundamentación teórica parecía prometer ${ }^{75}$.

\footnotetext{
73 Perspectiva que también puede apreciarse en parte del planteamiento de Muñoz Conde, cuando sostiene que "mal se puede reprochar... a un individuo que lesione o infrinja una norma que no le motiva en absoluto porque, por ejemplo, es la expresión de una situación que le oprime o le priva de sus derechos fundamentales"; cfr. Muñoz Conde, "El principio de culpabilidad”, p. 231. Sobre la concepción de Muñoz Conde, una valoración crítica global, cfr. Couso, "Fundamentos...", pp. 160 y s.

74 Tratadas con detalle en Couso, "Fundamentos...”, pp.263-268.

75 Así, no se plantea las dificultades de motivación del autor por la norma que encuentran su causa en déficit estructurales de la sociedad, ni mucho menos, las que la encuentran en el conflicto político y social, como, por ejemplo, la falta de participación del autor en los bienes protegidos por la norma. En materia de estado de necesidad exculpante,a su vez, Kindhäuser formaliza la motivabilidad por la norma, de un modo parecido a Jakobs, justificando ciertas hipótesis de "exigibilidad especial" en base al puro vínculo jurídico previo que obliga formalmente al autor a un mayor nivel de solidaridad (es decir, simplemente parafraseando al Código penal alemán), pero sin
} 
REJ - Revista de Estudios de la Justicia - No 11 - Año 2009

\section{Autonomia deliberativa y culpabilidad en Günther}

Günther se plantea la cuestión del fundamento material de la culpabilidad desde la perspectiva de la relación entre la "persona deliberativa" y la norma ${ }^{76}$. La condición de persona deliberativa depende de esa relación, y sólo puede ser culpable quien es persona deliberativa, pues sólo en ese rol puede poner en tela de juicio la norma, haciendo con ello necesaria en el plano comunicativo la imposición de una pena. La relación se da de distinta forma en las dos dimensiones en las que se manifiesta la persona deliberativa: como ciudadano (Staatsbürger), es persona deliberativa quien puede participar en el proceso político de creación de normas poniendo en ejercicio su capacidad crítica, lo que depende tanto de capacidades del sujeto (la de adoptar una posición razonada, en el debate político, frente a las opiniones ajenas) como de las condiciones democráticas del proceso nomogenético (el reconocimiento del derecho y la existencia de la posibilidad efectiva de participar); como "persona de derecho" (Rechtsperson), destinataria de las normas, es persona deliberativa la que, frente a la norma penal, tiene la capacidad actuar en base a (sus propias) razones, de tal modo que si lesiona la norma, la interpretación de esa lesión, en el plano comunicativo, encuentre su origen en el uso de aquella capacidad, sea que se trate de razones orientadas al entendimiento (como preferir no ser desleal con los que confían en el respeto de la norma), sea de razones puramente estratégicas (como la de querer evitar la pena) ${ }^{77}$.

Respecto de este último punto, Günther admite que la autonomía moral de la persona es incompatible con una pretensión de validez del contenido de las normas, de modo que, en su rol de ciudadano, la persona deliberativa debe tener plena libertad para una toma de postura crítica, de rechazo. Pero, en cambio, en su rol de persona de derecho, si el rechazo se traduce en lesión de la norma, se puede imputar esa lesión a su culpabilidad, siempre que la persona haya tenido autonomía deliberativa $^{78}$.

Interesante en el planteamiento de Günther es la relación que establece entre las dos formas -o momentos- de la autonomía deliberativa de la persona y la cuestión de la culpabilidad. De forma similar al camino seguido por Kindhäuser para fundamentar el deber de lealtad comunicativa, Günther atribuye relevancia para la culpabilidad material de quien lesiona la norma como persona de derecho, al hecho de que se haya decidido por la lesión, pese a haber contado con la posibilidad de expresar su desacuerdo con la norma desplazándose hacia su rol de ciudadano -para intentar en la arena política la modificación de la norma, convenciendo con razones a los demás participantes del proceso nomogenético-;

cuestionarse si, aún en esos casos, es posible que falte la relación interna entre autor y norma, a causa de determinadas constelaciones psicológicas pertenecientes al ámbito de las situaciones de necesidad (es decir, aún cuando no se dé un caso de abierta inimputabilidad).

${ }^{76}$ Günther, "Schuld...", pp. 252 y ss.

77 Ibíd., pp. 248 y ss, 254-255.

${ }^{78}$ Ibíd., pp. 248 y ss, 252-254. 
al no hacerlo, y expresar su desacuerdo como persona de derecho mediante la lesión de la norma "desconoce a la otra persona como un ciudadano y como una persona de derecho, igual a él, que confía en que la norma tiene validez" 79 .

Ya se indicó que la exigibilidad de este cambio de rol depende de que, como persona de derecho, el destinatario de la norma tenga la capacidad de tomar postura críticamente (en base a razones), capacidad que precisamente constituye la base del juicio de imputabilidad, sin importar aquí que a él individualmente le sea posible convencerse por las razones que intrínsecamente juegan a favor de la norma. En ese sentido, Günther no exige explícitamente una "motivabilidad racional por la norma", como la que yo he defendido en otro lugar ${ }^{80}$; pero en la práctica exige algo bastante similar, pues la "racionalidad" de las normas que, en mi opinión, debe ser accesible para los destinatarios de ella, no es una racionalidad que las normas puedan reclamar respecto de su contenido, sino una que deriva de la posibilidad ofrecida al destinatario con autonomía política de sentirse autor racional de ellas, gracias a su legitimidad discursiva (en el sentido y con las limitaciones con que los procesos políticos pueden adecuarse al principio discursivo). Para Günther, a su vez, si bien esa posibilidad de sentirse autor racional de la norma no es una condición de la autonomía deliberativa de la persona de derecho, sí es una condición de la autonomía deliberativa del ciudadano, y dado que "el Estado Democrático de Derecho vive del intercambio regulado e institucionalizado de los roles de ciudadano y persona de derecho", de modo que "el deber de cumplimiento de la norma (no) podría fundamentarse en la pura positividad del derecho, con independencia de su legitimidad" ${ }^{81}$, entonces, ese deber depende también no sólo de la posibilidad de una conformidad externa con la norma (suficiente para la autonomía deliberativa de la persona de derecho), "sino también de la institucionalización jurídica de procesos públicos de formación de opinión y toma de decisión, en forma de procedimientos democráticos, en los que las personas de derecho obligadas a evitar el injusto, puedan hacer valer eficazmente su toma de postura contraria a la norma", a tal punto que "Sin tales procedimientos, ¡no hay obligación de cumplimiento del deber ni hay culpabilidad en caso de lesión de la norma!” ${ }^{2}$.

Como puede apreciarse, en la práctica ese planteamiento hace fructífera, directamente en el campo de la culpabilidad, la falta de racionalidad discursiva de la norma respecto de los destinatarios de la misma que no gocen de autonomía comunicativa (en la nomenclatura de Günther: autonomía deliberativa en su rol de ciudadanos), de modo que, en realidad, contra lo que a primera vista podría parecer, para la concepción de culpabilidad de Günther no es suficiente que el autor pueda decidirse de forma puramente externa por la evitación del injusto, por meras razones instrumentales (zweckerational), pues hasta un esclavo podría decidir

\footnotetext{
${ }^{79}$ Ibíd., pp. 255.

${ }^{80}$ Couso, "Fundamentos...".

${ }^{81}$ Günther, “Schuld...”, pp. 248 y ss, 252-254.

${ }^{82}$ Ibíd., pp. 255-256.
} 
racionalmente, por conveniencia estratégica, acatar externamente las prescripciones de sus amos, lo que sería un acatamiento racional (-instrumental) pero heterónomo. Más bien se desprende del planteamiento de Günther la necesidad -que yo también he sostenido- de que la relación entre norma y autor le permita a éste cumplir con aquella de forma autónoma, es decir, como alguien que puede sentirse autor racional de ella.

Günther, sin embargo, como Kindhäuser, no llega a aprovechar todo el potencial de su teoría. La dimensión crítica-histórica de las condiciones de autonomía deliberativa (que Bustos toma como punto de partida) no está presente en su horizonte. Por ello, no llega a identificar la posibilidad de que, a pesar de existir esos procedimientos democráticos necesarios para la autonomía deliberativa del ciudadano, a muchos de ellos les falten las condiciones materiales o socioculturales para poder participar realmente del proceso de creación de las normas. Sobre todo, no llega a plantearse la cuestión de que la falta de toda posibilidad real de participación efectiva en los bienes tutelados impide al destinatario de la norma que se encuentra en situación de marginalidad, pese a la existencia de procesos democráticos formales, sentirse autor racional de las normas que protegen tales bienes ${ }^{83}$.

V. Aquí es donde me parece que los planteamientos de Bustos Ramírez pueden complementar correctamente los innegables aportes que las concepciones de Kindhäuser y de Günther ofrecen para una fundamentación material de la culpabilidad que permita hacerse cargo, respetando la autonomía del individuo, de la pregunta por la justicia de la imposición de pena (una pena preventivogeneralmente necesaria) a un individuo concreto.

Como se ha visto, Bustos Ramírez sitúa, con razón, los problemas de culpabilidad en el ámbito sociopolítico y sociocultural, contexto en el que la discriminación y estigmatización del inimputable como un ser irracional aparece como una arbitrariedad, pues la consideración de la dimensión política y el carácter positivo de las normas penales aporta una sana dosis de relativismo a todas las valoraciones. El enfoque político que Bustos Ramírez hace de la culpabilidad resulta de su acertada afirmación del carácter convencional (no natural ni ontológico) de las valoraciones realizadas por el legislador. Con ello, la relación

\footnotetext{
${ }^{83}$ Me parece que también se conforma con un limitado horizonte de condiciones de la autonomía deliberativa Feijoo Sánchez, "Retribución...", cuando, partiendo de presupuestos similares a los de Kindhäuser y Günther, afirma la irrelevancia normativa de los factores de desigualdad social que determinan una menor motivabilidad por las normas. De hecho, me parece que Günther no llega tan lejos explícitamente, y al menos en teoría deja abierta la puerta para que, atendiendo a realidades síquicas empíricamente dadas (que para Feijoo Sánchez parecen tener menor cabida), se determine -sin restricciones normativas a priori- quiénes se alejan del círculo de personas que en la esfera política se reconocen recíprocamente como iguales y libres (Schuld...”, pp. 256-257); así, un sistema político sensible a las diferencias materiales de capital político, social y cultural, que de hecho se parecían entre distintos grupos de la sociedad, podría verse reflejado en decisiones judiciales sobre culpabilidad igualmente sensibles.
} 
Couso - Culpabilidad y sujeto en la obra de Juan Bustos Ramírez

sociopolítica entre el individuo y el Estado que dicta las normas es decisiva para la cuestión de la culpabilidad.

Hasta ahí, en lo que se refiere al carácter contingente y meramente positivo, de la validez de las normas, hay una cierta coincidencia con el planteamiento de Kindhäuser y Günther. Incluso la hay, como señalé más arriba, en la identificación de una dimensión política en el juicio de culpabilidad, que depende de la relación entre individuo y norma, y finalmente, entre individuo y sistema social-estatal. Pero ahí donde Kindhäuser y Günther resuelven esa relación (para afirmar la culpabilidad) a partir de atributos más bien formales del ciudadano, que permiten atribuirle el rol de persona, Bustos Ramírez, en cambio, no se conforma con la atribución del rol de sujeto, sino que sostiene que la exigibilidad de responsabilidad criminal depende de una relación material (no formal), que efectivamente permita al individuo cumplir con su rol, advirtiendo que esa relación material, en más casos de los que Kindhäuser y Günther parecen contemplar, puede ser problemática, dado el conflicto entre "racionalidades" hegemónica y marginales. Con ello, Bustos Ramírez exige más que la posesión del estatuto normativo de sujeto: exige también condiciones materiales que hagan posible cumplir con las exigencias del derecho, condiciones que deben investigarse empíricamente, pues la culpabilidad tiene para Bustos Ramírez una dimensión cognoscitiva (y no meramente normativa). Como corolario, puede apreciarse que la concepción de Bustos Ramírez deja en mejor pie a los inimputables, cuya condición de sujetos - en alguna medida responsables, si bien bajo la forma de una responsabilidad penal general, no criminal- no es cuestionada, pues es una exigencia de la dignidad humana y la autonomía moral, que debe reconocerse a todos los ciudadanos, lo que supone un concepto de ciudadanía más inclusivo también. De esa forma, su concepción puede oponer exigencias garantistas derivadas de esa dignidad y autonomía moral, también respecto de la "segunda vía" del Derecho penal, exigencias que parecen tener menos apoyo en una concepción que les niegue a los inimputables el carácter de personas (como en el caso de Jakobs ${ }^{84}$, y también de Kindhäuser y Günther ${ }^{85}$ ).

Por su parte, como ya señalé, los aportes tomados por Kindhäuser y Günther desde la teoría del discurso, permiten relevar la importancia, ignorada por Bustos Ramírez, de la autonomía comunicativa en el plano de los procesos democráticos y participativos de creación de normas, para que un derecho meramente positivo, pueda ser seguido autónomamente por su destinatario. Sin esa condición de autor de las normas, me parece que la exigibilidad social, incluso si se basa en que el sistema social-estatal ha ofrecido al individuo condiciones

\footnotetext{
${ }^{84}$ Jakobs, "Verabschiedung...".

${ }^{85}$ En mi opinión -extrapolando en alguna medida el planteamiento de Nino-, la segunda vía del Derecho penal también tiene que responder de forma compatible con la autonomía moral del individuo, la pregunta por la legitimidad de la imposición de una medida de seguridad necesaria para la sociedad, pero aflictiva para el individuo al que se le impone. Cfr. Couso, "Fundamentos...", pp. 446 y ss.
} 
REJ - Revista de Estudios de la Justicia - No 11 - Año 2009

materiales para cumplir con tales exigencias, no asegura a éste la posibilidad de un cumplimiento autónomo. Ahora bien, en mi opinión, la relación entre individuo y norma, e individuo y Estado, determinada por las condiciones de creación de las normas y por su relación con los bienes protegidos penalmente, no es decisiva desde el punto de vista de la posibilidad de exigir legítimamente algo del individuo, sino desde el punto de vista de la posibilidad del individuo de motivarse por esas normas, que a su vez incide en su posibilidad de evitar la pena ${ }^{86}$. Y la evitabilidad de la pena, por su parte, es condición de la legitimidad de su imposición a ese individuo concreto, que es precisamente aquello que un concepto material de culpabilidad debe asegurar.

\footnotetext{
${ }^{86}$ En consecuencia creo que la búsqueda de un fundamento del deber individual de cumplir con la norma (que explique por qué el individuo a quien se le exige, si además puede, debe) es inútil: no existe deber individual, y por tanto en rigor no hay "exigibilidad social"; sólo hay necesidad preventiva de pena frente al incumplimiento, que, sin embargo, puede ser compatible con la autonomía individual si jel autor "consiente" en que se le imponga la pena!; cfr. sobre ello, Couso, "Fundamentos...", pp. 400 y ss. y 413 y ss., siguiendo el principio de asunción de pena, de Nino.
} 
Couso - Culpabilidad y sujeto en la obra de Juan Bustos Ramírez

\section{BIBLIOGRAFIA}

ACHENBACH, HANS: "Historische und dogmatische Grundlagen der strafrechtssystematischen Schuldlehre", Berlin, 1974 (cit. "Historische und dogmatische...").

ALBRECHT, PETER-ALEXIS: "Unsicherheitszonen des Schuldstrafrechts", GA, 1983 (cit. "Unsicherheitszonen...”).

BUSTOS RAMÍREZ, JUAN: "Revisión crítica de la imputabilidad a la luz de la teoría de las subculturas y la psiquiatría alternativa”, en Mir Puig (ed.), Derecho penal y ciencias sociales, (cit. "Revisión crítica...").

"Imputabilidad y edad penal", en Libro-Homenaje a Beristain, Donostia - San Sebastián, 1989.

(director) Un Derecho penal del menor, Santiago de Chile, 1992.

"Hacia la desmitificación de la facultad reformadora en el derecho penal de menores: por un derecho penal del menor", en el mismo (director) Un Derecho penal del menor (cit. "Hacia la desmitificación...”).

"Manual de Derecho penal. Parte general", $4^{a}$ ed. aumentada, corregida y puesta al día por Hormazábal Malarée, Barcelona, 1994 (cit. “Manual...”).

"Los menores y el Derecho penal", Derecho privado y Constitución, No 7, 1995.

COUSO, JAIME, "Fundamentos del Derecho penal de culpabilidad". Historia, Teoría y Metodología", Tirant lo Blanch, Valencia, 2006 (cit. "Fundamentos...”).

FEIJOO SÁNCHEZ, BERNARDO: "Retribución y Prevención General. Un estudio sobre la teoría de la pena y las funciones del Derecho Penal", Editorial B. de F., MontevideoBuenos Aires, 2007.

GARCÍA AMADO, JUAN ANTONIO: "La Filosofía de Derecho de Jürgen Habermas", Doxa13, 1993 (cit. "La filosofía...”).

GARCÍA ARÁN, MERCEDES: “Culpabilidad, legitimación y proceso”, ADPCP, 1988.

GIMBERNAT ORDEIG, ENRIQUE: “¿Tiene un futuro la dogmática jurídicopenal?”, en el mismo, Estudios, publicado por primera vez en España en Problemas actuales de Derecho penal y procesal, Salamanca, 1971 (cit. “¿Tiene un futuro...?”).

GÜNTHER, KLAUS: „Schuld und kommunikative Freiheit. Studien zur personalen Zurechnnung strafbaren Unrechts im Demokratischen Rechtsstaat",

Vittorio Klostermann, Frankfurt am Main, 2005.

HABERMAS, JÜRGEN: "Faktizität und Geltung. Beiträge zur Diskurstheorie des Rechts und des demokratischen Rechtsstaats", 4a ed., Frankfurt am Main, 1994 (cit. "Faktizität...").

HASSEMER, WINFRIED: "Fundamentos del Derecho penal", traducción de Arroyo Zapatero y Muñoz Conde, Barcelona, 1984 (cit. "Fundamentos..."). "Einführung in die Grundlagen des Strafrechts”, 2a ed., München, 1990 (cit. "Einführung...2.”).

“¿Alternativas al principio de culpabilidad?”, traducción de Muñoz Conde, CPC, 1982 (cit. “¿Alternativas...?”).

JAKOBS, GÜNTHER: "Schuld und Prävention”, Tübingen, 1976 (cit. "Schuld und Prävention”). "Das Strafrecht zwischen Funktionalismus und "alteuropäischem" Prinzipiendenken. Oder: Verabschiedung des "alteuropäischen" Strafrechts?”), en ZStW, 1995 (cit. "Verabschiedung...").

JIMÉNEZ REDONDO, MANUEL: "Estudio preliminar", en Vives Antón, Fundamentos del Sistema penal, Valencia, 1996 (cit. "Estudio preliminar...”).

KINDHÄUSER, URS: “Rechtstreue als Schuldkategorie”, ZStW, 1995 (cit. "Rechtstreue...”).

MUÑOZ CONDE, FRANCISCO: "El principio de culpabilidad", en III Jornadas de Profesores de Derecho Penal, Universidad de Santiago de Compostela, 1975.

"Über den materiellen Schuldbegriff", GA, 1978 (cit "Über den materiellen...".

NINO, CARLOS SANTIAGO: "Los límites de la responsabilidad penal. Una teoría liberal del delito”, Buenos Aires, 1980 (cit. “Los límites...”). 
REJ - Revista de Estudios de la Justicia - No 11 - Año 2009

PÉREZ MANZANO, MERCEDES: “Culpabilidad y Prevención: Las teorías de la prevención general positiva en la fundamentación de la imputación subjetiva y de la pena”, Madrid, 1990 (cit. "Culpabilidad y prevención...").

ROXIN, CLAUS: “¿Qué queda de la culpabilidad en Derecho penal?”, traducción de Silva Sánchez, CPC, 1986.

"Strafrecht. Allgemeiner Teil, Band. I. Grundlagen. Der Aufbau der Vebrechenslehre", 2" ed., München, 1994 (cit. "Strafrecht...”).

STRATENWERTH, GÜNTHER: "El futuro del principio juridicopenal de culpabilidad", traducción de Bacigalupo Zapater, Madrid, 1980. 